\title{
Getting into DAM project activities and experiences of digitizing news broadcast production
}

\begin{abstract}
Niklas Krantz
is a TV reporter who worked at Rapport, the leading national news-show in Sweden. In 1994, he created one of the first news services on the web, based on a daily Rapport news bulletin and the SVT teletext content. In 1997, he formed the Diginy project which identified the needs for new technology, and in the coming 5 years he served as project leader for the launch of the digital news channel SVT 24, for DigiNoF, digitalization of all the News and Sports at SVT in Stockholm. Since 2002 he has been project manager for editorial systems, forming a multimedia integrated system for TV production on all levels at SVT.
\end{abstract}

Keywords: archive, cost reductions, digital production, workflow, transition

Abstract Swedish Television was one of the first broadcasters in the world using a DAM for news production and archives. The project was set to make a break even in 5 years. But already in 4 years the investments had paid for itself and led to cost savings of more than 10 per cent a year, combined with an increased output to air and the web. The cost reductions are not the result of the new technology itself, but caused by a new organization and new workflows made possible by the new digital production system. The remodeling of the business process has not been without problems. This article describes the traps and experiences that will meet any broadcaster entering the transition to digital production and asset management.

Journal of Digital Asset Management (2006) 2, 138-142. doi:10.1057/palgrave.dam.3650031

\section{THE SVT BUSINESS CASE FOR DAM IN BROADCAST}

Once engineers in broadcast thought that going digital meant switching from an analo to a digital video signal, SDI. Today we know it means handling video files on a network, playing them out from servers and filing them in their data format.

To do this we need a brain that keeps track of all the files and their assets, in the system, a Digital Asset Management System. We also need a circulation, a system that moves the media around, does the naming of the files and deletes them, unless we want to employ a lot of people doing that. This is sometimes called a Media Management System.

Five years ago, when we went out requesting Niklas Krantz Newsroom Development, Sveriges Television, Stocholm 10510 Sweden

Tel: +4687848560 Mobile: +46708847737

E-mail: niklas.krantz@svt.se a tender for a new system for the News and Sports Department at SVT, we stipulated we needed both of those functions. And we found out that nobody could offer it. So we had to build it ourselves. For our help we had a company that 2 years earlier had made our robotic video archives in our digital pilot, the $24 \mathrm{~h}$ news channel SVT 24 . They were called Ardendo and worked together with IBM.

We also made an investigation on how much we could cut down costs by moving to digital production. And we found out that we would gain nothing only by switching technology.

\section{Public service means spending the money in the most efficient way}

Swedish Television is a public service company of the European model, inspired by the BBC.

The government do not own us, but control the economy by regulating the license fee that everybody with a TV set has to pay. We were once a television monopoly in Sweden, but today we have to compete with three other big channels and a lot of smaller ones, all of them financed by advertising. We are not allowed to have any commercials besides sponsoring signs before and after some events.

This means we cannot argue for investments that would raise our income. The only argument 
is that new, more efficient technology could make some necessary changes possible, by reducing the costs.

\section{SVT is no longer a TV company}

Once there was one channel in Sweden. Then came TV2, also from SVT. Then came nothing, but color TV. Then came the commercial TV3, TV4, Channel 5 and the cables. Our answer was our technology pilot and digital terrestrial news channel, SVT 24 and the Children's Channel, combined with the Knowledge Channel (a cooperation with the UR, Swedish Educational Broadcasting Company). And of course the next step was the rewarded number one web-site in Sweden, svt.se, with material from our archives available online and on demand streaming over the net.

To become a multimedia company, instead of a television company, based on the same income, you need to change the way you use your money.

Obviously IT technology is cheaper than broadcast technology (if you do not buy it from the old broadcast vendors who sell new technology at old high prices). But our old machines have been rolling for 15-30 years, and new computers have to be replaced at an interval of 3-10 years. So even if we cut down our invested capital to a third, the yearly cost will not change dramatically.

The secret is that with the new systems, you can change the organization and the workflows. But then you also have to change the way you think. And this is the hardest part, for everybody, from top to bottom.

\section{Reasons for change}

Everybody in a company wants to do what is best for the company. Although sometimes other interests, closer to oneself, will dominate. So if the management sees the cost reductioning and multimedia publishing as number 1 , there could be other reasons for other groups that would motivate them for a change.

The journalists will take advantage of new technology to achieve:

\section{Better storytelling}

A digital environment will make it easier to gather information and pictures they need, to put together a good piece.

\section{Faster workflow}

If you can grab an incoming feed immediately, cut it on the fly and pass it over to play out, the news department has an excellent tool to compete with other newsrooms, television as well as radio and the net. When designing a new system, it is important to minimize the number of steps and time-consuming processes. At SVT we do not import the material before we start editing. We do it on the fly in the edit suite. If you import all the raw material before editing, it is important that the ingest and editing can be done in parallel.

\section{Control over the creative process}

I like to drive my car myself. Others prefer having a driver. As a journalist I like to push the buttons myself, instead of instructing an editor. But a professional video editor can really do wonders when working with a complex story. Our experience is that you need to work in both ways, for many years to come. But the time will come when a video editor will be as rare as a private secretary today.

\section{Stability}

For a journalist an earthquake is exciting, but a $10 \mathrm{~min}$ breakdown in the media management system means at least the end of the world. But with a working strategy of how to work around it, when things happen (because they will, whatever anybody promises), then they (and you who are responsible) may survive.

The technicians could easily be divided into two groups. Those who know the new technology and those who do not. Some of those who do not will be able to learn, some not. And almost nobody will learn enough to become a real specialist.

The motives for the board are as mentioned:

\section{Fewer people}

Especially among the technology professions you will need less staff. Our strategy has been to try to multiskill everybody and make the same people performing both journalistic and technology tasks. This makes the organization more flexible.

But don't forget: You will need some more people on IT support and system management. 


\section{Fewer investments}

This is harder to achieve, if you count costs per year. When you make the change, you will have higher costs, and after some years you will realize some vendors charge immensely high support license fees and you will have to reinvest earlier than you thought.

\section{Increased output}

News will go on for $24 \mathrm{~h}$ per day, and new channels and new media types will be added. SVT has launched the parole: "More program for the money".

\section{They all are threatened}

\section{Users}

Why change something that works? Everybody has to start learning, and everybody will make mistakes that the public will see and comment upon. In the beginning some edits will look worse. Some jobs will disappear and perhaps you or your best friend will get fired.

\section{Unions}

Their members will feel bad and they will come under tremendous pressure to do something, no matter if it makes any difference or not.

\section{Politicians}

The new technology made it possible for our newsrooms to work with the same material. Instead of sending out four crews to a press conference, reporting the same story, we would send one crew and edit four or 10 different versions of the story during the day. To achieve that, we had to merge the three or four newsrooms in Stockholm together into one big news organization. Before, the politicians could play out the journalists against each other, but now they were all playing in the same team.

\section{Bureaucracy}

As we were reorganizing, the need for administration went down. Even if that corridor has grown a little since, there are much fewer people than before.

\section{META - a news production system}

The system we have created is a news production system for the whole of Sweden. It is used by approximately 10 newsrooms in
Stockholm, and 10 newsrooms with their own newscast in the regions. All of them are connected through a WAN (at the time we started in 2001, it had a bandwidth of $34 \mathrm{Mb} / \mathrm{s}$, today $2.5 \mathrm{~Gb} / \mathrm{s}$ ). The video play play-out and ingest was done by the SGI video servers (we had 34 of them).

A big SGI server was the hub, our central server, which handled all the file transfers around the system via ftp. The ground base on which we built the system was our already existing IBM Magstar tape robotic archives, later IBM LTO and today a Spectra Logic. This is the place where we file all aired stories and keep feeds for 30 days. The browse copy is kept on line on cheap disc, for immediate use.

All edits are done on Avid NewsCutters, from where you "post" the stories to the system via ftp. There were over $90 \mathrm{NC}$ :s in the beginning, which made this the biggest networked Avid system in the world.

A crucial point was the naming of the stories, as every story must have a unique name that could not be changed, as we were operating with multiple copies of every story on the network. The names were created in the Avid Newsroom system, with a naming convention based on rundown and date. The file name was then cut and pasted into the name field in the Newscutter. As the Meta system was picking up everything from Avid News, metadata could be extracted from the production system and paired together with the filename, without anybody doing any extra logging work.

The cut and paste naming is the weakest part in the system and depends on problems integrating Avid News with the media management. Therefore, the next version of META will contain a rundown module with an automatic naming function in the background.

For browsing and selection of choosing material to edit, there is a tool called PreCut. To add and time CG:s, we have a similar tool to be used to add control information for effects while playing out. It can also be used for choosing new in- and out-points in the video file. We call it PreTime.

Ordinary graphics are done by journalists, or on air producers through a WYSIWYG interface. It is an application made by SVT based on Shockwave. You take any jpeg or tiff picture, rotate or zoom them and place in a 
prepared template. The application will do the naming and transfer the picture to the right play-out module. More advanced graphics, often with animations and 3D, are created in one of our two graphic centers and transferred to the play-out site over the network.

For scheduled recording and ingest to the system we are using a tool, DART, which Ardendo made on our request. We use it to control 12 video channels, but it can do more. CNN is now using it, controlling more than 50 channels at a time.

Play-out is controlled by our own software, called Hawrys. In the first version you choose play-out channel and play-out pushing buttons on a keyboard. In the new automatic version you only push the "next" button and the system finds the right media and the right hardware to play it on.

The META system, the real DAM, is the users' interface to find and see all the other tools. META is a DB2 database that keeps track of everything. But it is also a series of scripts and rules that takes care of all background tasks, initiated by actions in rundowns, ingest stations, play-out servers, video editors etc.

This system has been up and running since 8 September 2001. We are now preparing for the next version that will include all program production at SVT. This means a much more advanced database, a larger scale and a fully integrated system.

\section{META goals in $\mathbf{2 0 0 0}$}

When we started the digitalization project for News and Sports in Stockholm, the META project, in the year 2000, we had set some goals. With us we had the experiences of our digital news pilot, SVT24, launched in 1999. As a by-product we also had a national $34 \mathrm{mb} / \mathrm{s}$ IP network with video servers in each of our 10 regions, using and delivering to our SVT24 video archives, DVCPRO 25 video files, over the network.

Besides faster news, cheaper technology and better graphics, the hard nut to crack was how to lower the costs. The goal was set at 10 per cent, which would mean a break break-even in 4-5 years.

One great cost-saver was the new organization. Another one was having fewer video editors. Not everything, but the simple edits should be done by the journalists themselves, as they already did at SVT24. The unions refused, unless the company paid the journalists for doing a new job. The company said no, and that everybody has to learn new skills, so why should only the journalists be paid extra? For an year, no journalist touched the specially designed journalist Newscutters we had installed. At last the journalists got their 50 EUR extra a month, due to the union pressure, and reporters slowly started joining the journalist editing training courses, although it took another year before people were queuing for the journalist editing suites. Two years behind schedule, the number of video editors was finally according to the plan.

Some other reductions were made in the control room and the studio. The production assistants, or script girls as we used to call them, were functions that were removed. Before the change there were 22 people working in the control room, the VTR-room and the studio. Today they are 12 during a big show play-out. In the regional news they are, with our new automation system, between two and four people. That includes the presenter.

The VTR operators are, of course, gone. Play-out is handled by what we call an on air-producer, who plans the show, decides when things should happen and also pushes the button. In simple news bulletins, cameras are remote controlled, the prompter is run with a foot pedal by the anchor and no studio man is pointing at the actual camera for the anchor. By using a common studio for three control rooms with around 10 different sets, we can use a common lighting equipment and crew.

Another important cost saver is the termination of the VHS. Not the tape costs, but all the time spent recording, transporting and keeping track of all those cassettes. And one of the most exciting things we saw was that the browse video, which was available at all desktops, and was really a magic that motivated everybody to use the new system with joy. Suddenly, you could view any story or feed wherever and whenever you wanted.

We probably could have saved up to 20 per cent of the costs. However, we made a choice to use half of the margin to increase the output, both in volume and in quality. A new cultural 
news bulletin at $0700 \mathrm{~h}$ was launched and a new research desk was installed.

Combining cost savings with more and better content made it much more attractive to everybody.

\section{Maintenance and support of DAM}

A traditional broadcaster has a service department, which is handling maintenance of the video equipment. Mostly another department is supporting and running the IT-network. When you go digital you could build a brand new production network and teach the service people how to work with computers. But then you will have two parallel organizations and two parallel networks. And one day you will have to integrate them, because you will need to access the Internet even from the production system.

We started 10 years ago forming a common IT and service department. And we are still reorganizing and retraining people to get the right skills in the right place.

We have one network for everything, but as we have been using it more and more for crucial and heavy tasks, such as file transfers, live streaming and play-out to air, we have sectioned and switched it and built internal firewalls around control rooms. We have had virus attacks of viruses, mainly on edit equipment, and some broadcast storms. But it has never taken us out of the air, and the advantages of having a common network are much higher than the risks.

We are still changing the internal service agreements. When using computers, only for news texts, this is something the IT people could handle from home over a modem. But with a production system based on computers, you need to have people in place at work on site for almost $24 \mathrm{~h}$ a day.

\section{Making it work}

Technically, it was working quite well from the beginning, even if we of course had got some bugs to terminate fix. Always keeping a back-up workflow was a way to avoid damage when having problems. It is also important that the crew feels confident with the system. If they worry all the time, they can not do a good job even when the technology does not fail.

But more important was getting everybody on the train, by discussing the pros and cons before making the change. Make everybody prepared and motivated! It is important to be able to see with your own eyes the way to do it. As this was impossible for us, being among one of the first ones trying, we made our own test pilots. The news channel SVT 24 was both a technology pilot and a way to explore new ways to work. It would have been easier to visit another station to see it, but it could be a good idea anyhow, to start in a small area and expand when you get the knowledge and motivation to do so.

But however more you prepare, there will always be some thresholds you need to cross. When switching to digital, you will need to spend some more money, on the project. You will also need more people for a period, when you train for the new methods, perhaps work in parallel with the old technology, and before you get into the routines of working really safe and fast. And there will always be a period when people complain, probably want to stop the process, and when everybody who did not dare to say anything before, take the chance to say: It will never work.

But on condition that you will surmount that those obstacles, you could create a success. At least this is what our users have claimed we have done. But now they want more... and there is nothing good enough out there yet! 